\title{
From regional climate simulations to the hydrological information needed for basin scale impact studies
}

\author{
I. Portoghese ${ }^{1}$, E. Bruno ${ }^{1,2}$, and M. Vurro ${ }^{1}$ \\ ${ }^{1}$ Water Research Institute, National Research Council, Bari, Italy \\ ${ }^{2}$ Dept. of Water Engineering and Chemistry, Polytechnic of Bari, Bari, Italy \\ Received: 18 February 2010 - Revised: 17 March 2010 - Accepted: 18 June 2010 - Published: 30 June 2010
}

\begin{abstract}
The accuracy of local downscaling of rainfall predictions provided by climate models is crucial for the assessment of climate change impacts on hydrological processes because the presence of bias in downscaled precipitation may produce large bias in the assessment of soil moisture dynamics, river flows, and groundwater recharge.

In this study, the output of a regional climate model (RCM) is downscaled using a stochastic modelling of the point rainfall process able to adequately reproduce the daily rainfall intermittency which is one of the crucial aspects for the hydrological processes characterizing Mediterranean environments. The historical time-series from a dense raingauge network were used for the analysis of the RCM bias in terms of dry and wet daily period and then to investigate the predicted alteration in the local rainfall regime. A Poisson Rectangular Pulse (PRP) model (Rodriguez-Iturbe et al., 1987) was finally adopted for the stochastic generation of local daily rainfall as a continuous-time point process with forcing parameters resulting from the bias correction of the RCM scenario.
\end{abstract}

\section{Introduction}

Remarkable research efforts have been thus far addressed to understand the predictability of the climate system by improving the climate model physics, resolution, and parameterizations for unresolved processes, which result in the development of high-resolution Global Climate Models (GCMs) and Regional Climate Models (RCMs). Nevertheless, the simulated climate behaviour is still far from being consistent across the range of space and time scales which is basically needed to undertake impact studies.

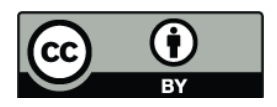

Correspondence to: I. Portoghese (ivan.portoghese@ba.irsa.cnr.it)
To obtain realistic atmospheric forcing from climate models to be used in impact study methods for scale-bias correction of the output variables are needed (Déqué, 2007). In particular, the space-time properties of rainfall fields have been recognized as one of the fundamental issues in the analysis of hydro-climatologic processes in order to improve the observation and modelling techniques (Deidda 2000; Deidda et al. 2006). Starting from large scale atmospheric states predicted by global and regional models, different approaches are proposed in the literature to attempt an adequate reproduction of the local phenomenon and their statistics. Among the several mathematical approaches, those based on point process were proved particularly suitable and well adapted when extreme rainfall events of convective nature are considered (Salson and Garcia-Bartual, 2003).

\section{Data and methods}

Before any bias correction method is developed and implemented it is important to investigate the predictive performance of the adopted climate model. An investigation based on the intermittency features of the daily rainfall process has been undertaken using meaningful statistical descriptors corresponding to PRP parameters which characterize the alternating renewal process of the so called wet-dry spell model (Eagleson, 1978). Then, the PRP parameterization based on RCM projections and local observations has been adopted for the synthetic generation of daily rainfall.

\subsection{RCM and observed rainfall series}

The output of a high-horizontal-resolution RCM named EBU-POM (Gualdi et al., 2008), has been adopted which was specifically developed for Southern Europe, Mediterranean and the Balkan areas by a scientific cooperation by the Italian INGV, the Serbian Republic Hydro Meteorological Service (RHMSS) and the University of Belgrade (UB). A control

Published by Copernicus Publications on behalf of the European Geosciences Union. 


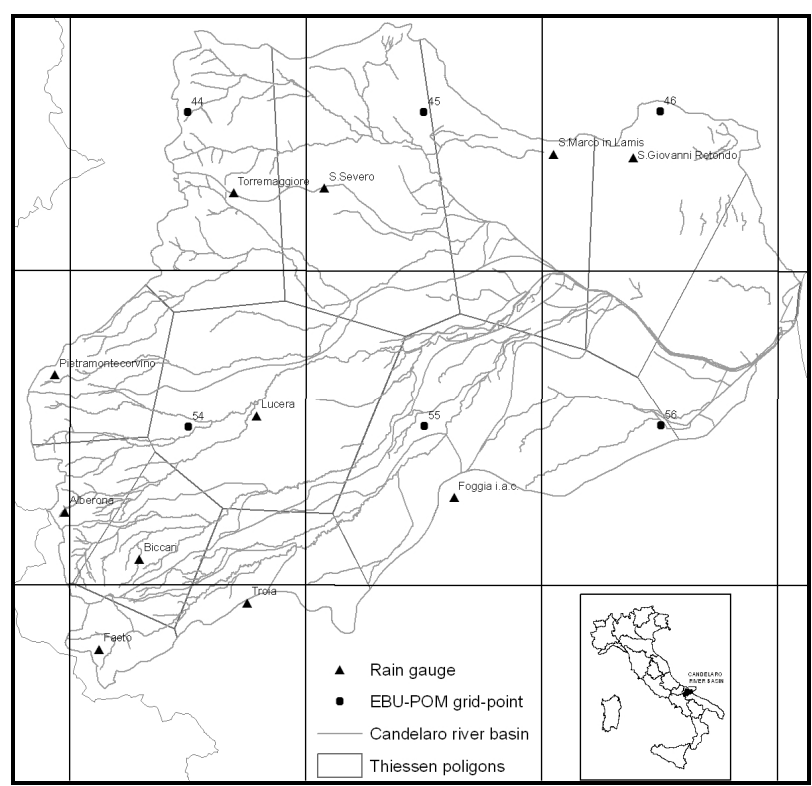

Fig. 1. The rainfall network of the Candelaro river basin and the corresponding RCM grid-cells.

run spanning over 30-year period (1961-1990), and one covering the first part of 21st century (2003-2030) under SRES scenario A1b were considered.

The study area refers to six model cells covering about $2000 \mathrm{~km}^{2}$ of the Candelaro river basin (Fig. 1), a semi-arid catchment facing the Adriatic coast of Apulia in Southern Italy. This basin is part of the rural case study in the CIRCE research project, aiming to assess the climate change scenarios and impacts in the Mediterranean region.

The observational dataset consists of twelve historical daily series from the national gauge network extended for the same period of the model's control run and covering the basin area.

In the analysis, we have compared the rain gauge records with the six model grid-cells, each with a size of $21 \times 27 \mathrm{~km}^{2}$, covering the study area. To operate this comparison the daily observations have been averaged over the grid cell domains. Basically, the daily observations have been weighted on representative areas of the rain gauge stations falling into each grid cell. The representative areas were delineated by the Thiessen polygons around each rain gauge station and therefore the observations correspond to area-weighted values clipped on the RCM grid (Fig. 1). The analysis was performed considering each of the RCM grid cell separately while the results reported in Sect. 3 refer to the data from one single grid-cell corresponding to the upper part of the catchment where the topographic heterogeneity is more evident. The grid-cell adopted for the local scale analysis is indicated in Fig. 1 with the RCM node 54.

To analyze the intermittency properties of rainfall series both the RCM control and scenario, and the observed

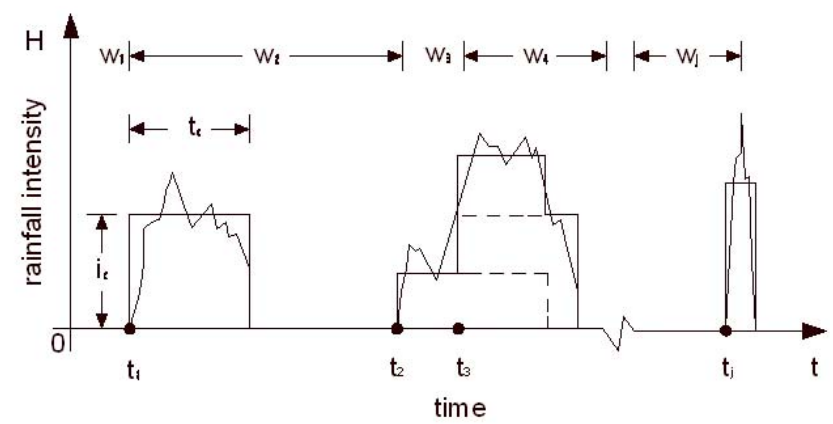

$W_{\mathrm{j}}=$ inter-arrival time of events (pulses)

$t_{\mathrm{ci}}=$ duration of $\mathrm{i}$-th pulse

$\mathrm{i}_{\mathrm{i} i}=$ intensity of the i-th pulse

Fig. 2. Schematic representation of PRP model (Rodriguez-Iturbe et alii, 1987)

datasets were decomposed into dry and wet clusters of days, and average daily intensity calculated for each wet period.

\subsection{PRP model and stochastic generation of local precipitation scenarios}

In the PRP model according to the scheme by RodriguezIturbe et al. (1987) the rainfall process is represented by a temporal sequence of rectangular pulses with random average storm intensity $i_{c}$, and a random duration, $t_{c}$ (Fig. 2). The occurrence of rainfall events is modelled by a Poissonian process with the storm arrival rate represented by a parameter $\lambda$. The rainfall intensity at a given time is obtained as sum of intensities of all occurred overlapping storms at that instant. Moreover, it is assumed that the event characteristics (duration, storm intensity, and inter-arrival time) are random variables independent from the occurrence time and identically distributed. At the basis of the storm description in the PRP model, it is assumed that $i_{c}$ and $t_{c}$ are exponentially distributed, with parameter $\mu_{I}$ (mean intensity of pulse) and $\delta_{w}$ (mean duration of the pulse) respectively. By assuming the PRP scheme, three parameters (duration, storm intensity and inter-arrival time) are used to represent the point rainfall process.

The stochastic modelling of local rainfall process explicitly allows for a re-parameterization based on projected statistics derived from climate models (Burlando and Rosso 1991, 2002; Kilsby et al., 2007). Therefore, under the reasonable hypothesis that the model mismatch is due above all to an imperfect parameterization of the precipitation physics, we could derive the expected alteration of rainfall regime from the scale factor obtained as ratio between the PRP parameter for 21 th century run $\left(21_{c}\right)$ and the control run $\left(20_{c}\right)$, through following Eq. (1):

$\vartheta_{i}^{*}\left(21_{c}\right)=\vartheta_{i}^{\mathrm{OBS}}\left(20_{c}\right) \frac{\vartheta_{i}^{\mathrm{RCM}}\left(21_{c}\right)}{\vartheta_{i}^{\mathrm{RCM}}\left(20_{c}\right)}$ 
a)

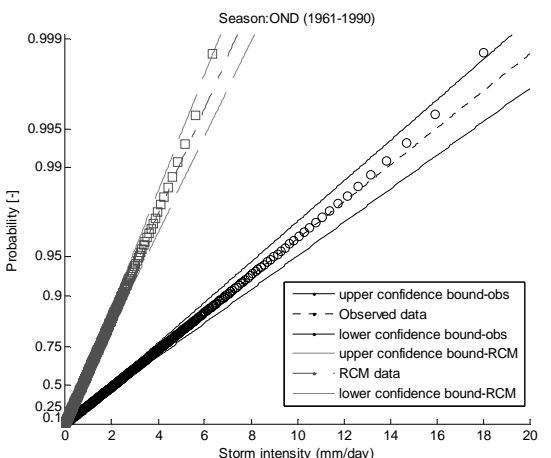

b)

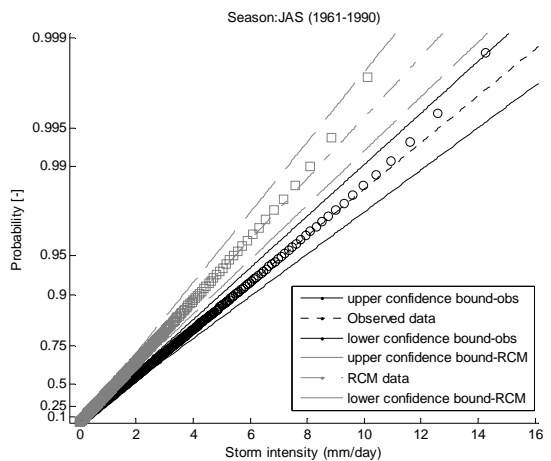

Fig. 3. Exponential probability plots for the storm intensities computed from the reference observations (with circles) and the RCM (with squares), using data from a single grid-cell. Straight lines represent the corresponding theoretical distributions with their respective $95 \%$ confidence bands for autumn storm intensities (a) and summer storm intensities (b).

a)
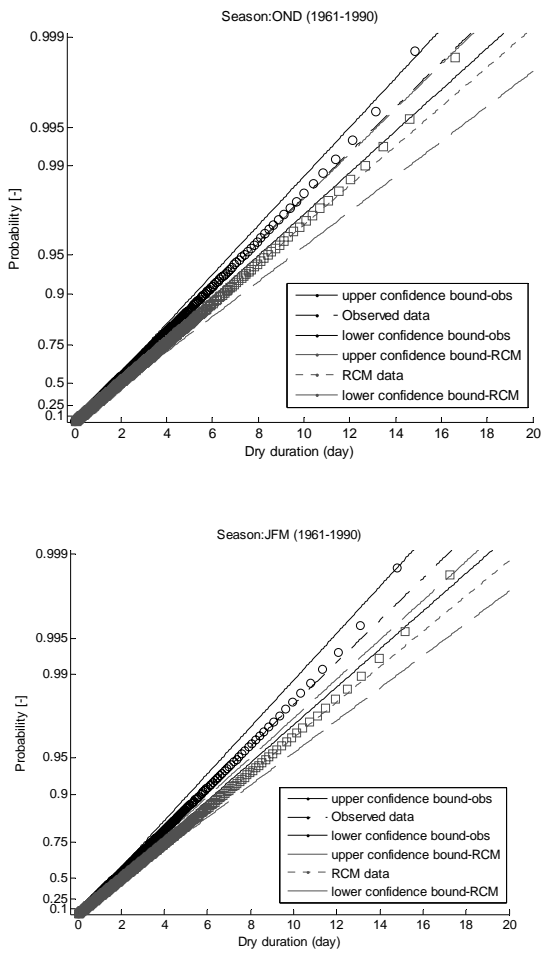

C) b)

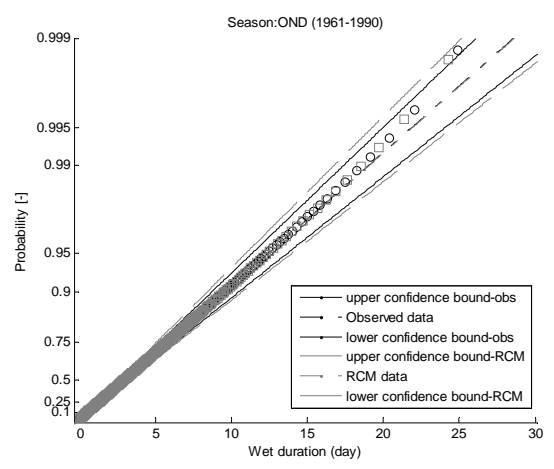

d)

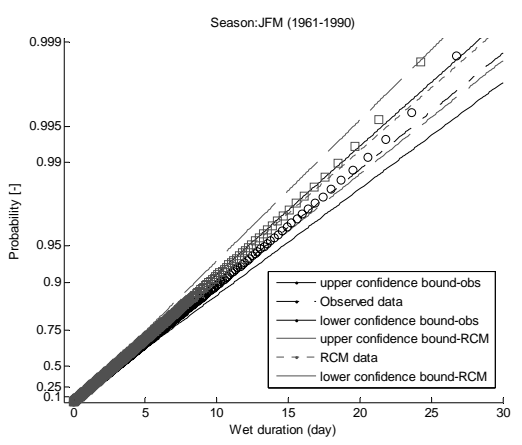

Fig. 4. Exponential probability plots for the wet and dry periods in autumn (OND) and in winter (JFM) computed from the reference observations (with circles) and the RCM (with squares), using data from a single grid-cell. Straight lines represent the corresponding theoretical distributions with their respective 95\% confidence bands for autumn dry periods (a), autumn wet periods (b), winter dry periods (c), and winter wet periods (d).

Where $\vartheta_{i}^{*}$ represents a generic statistical parameter of storms to be used in constraining some stochastic rainfall model while $\vartheta_{i}^{\mathrm{OBS}}$ and $\vartheta_{i}^{\mathrm{RCM}}$ are the correspondent parameters respectively extracted from the observational dataset and from the RCM-simulated time-series.

\section{Results}

The storm parameters adopted in the PRP scheme, namely mean storm intensity $\left(\mu_{I}\right)$, mean wet duration $\left(\delta_{w}\right)$ and mean dry duration $\left(\delta_{d}\right)$, were seasonally derived for the reference period (1961-1990) from the corresponding series of the RCM and observations. 
a)
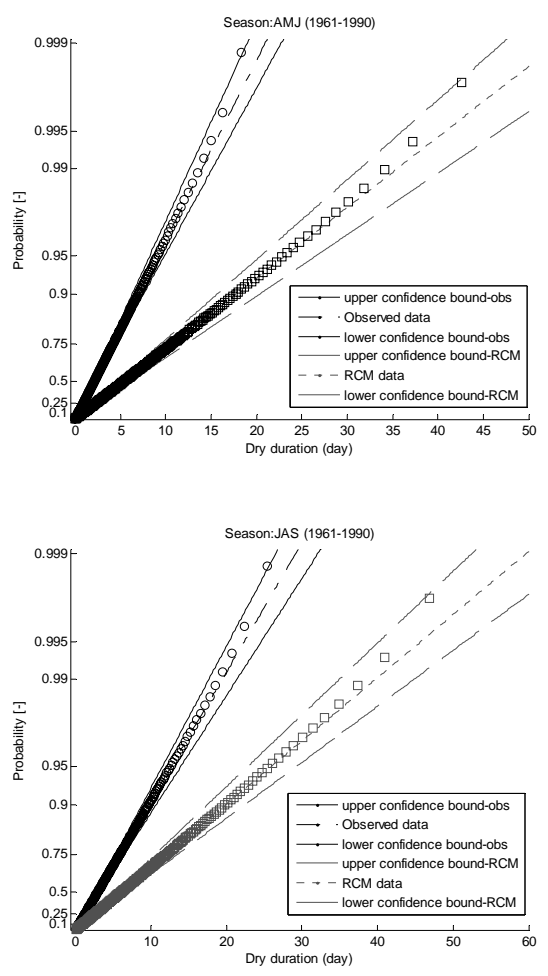

c)

Fig. 5. Same as Fig. 4, but for spring (AMJ) and summer (AMJ).

The exponential probability charts were used to evaluate the fitting of the storm characteristics to the theoretical distributions and compare the climate model output against daily rainfall observations. The ordinary component of the observed and modeled variables reasonably follow the theoretical distribution (Figs. 3, 4, and 5) under the assumption that the upper threshold of ordinary rainfall is considered equal to the 90th percentile. Furthermore, to assess the statistical meaningfulness of distributional differences, the $95 \%$ level confidence bands were derived by using the percentile bootstrapping technique by Kottegoda and Rosso (2008). According to the confidence bands, the distributional differences were statistically meaningful for storm intensity in all seasons (autumn and summer seasons showed in Fig. 3), for wet periods only in the spring season (Fig. 5b), and for dry periods in spring and summer seasons (Fig. 5a and 5c). In other words, the RCM simulation for the reference period yielded an underestimation of the storm intensity in all seasons particularly in autumn and winter, an overestimation of the length of the dry periods in spring and summer, and a good agreement for the wet durations in autumn and winter.

The analysis of model-observation bias was also performed through the ratio between each PRP storm parameter (Table 1) derived as maximum likelihood estimations parameter of the corresponding exponential distribution. The model bias can be summarized into a poor capability to represent the intermittency of the daily rainfall particularly for b)
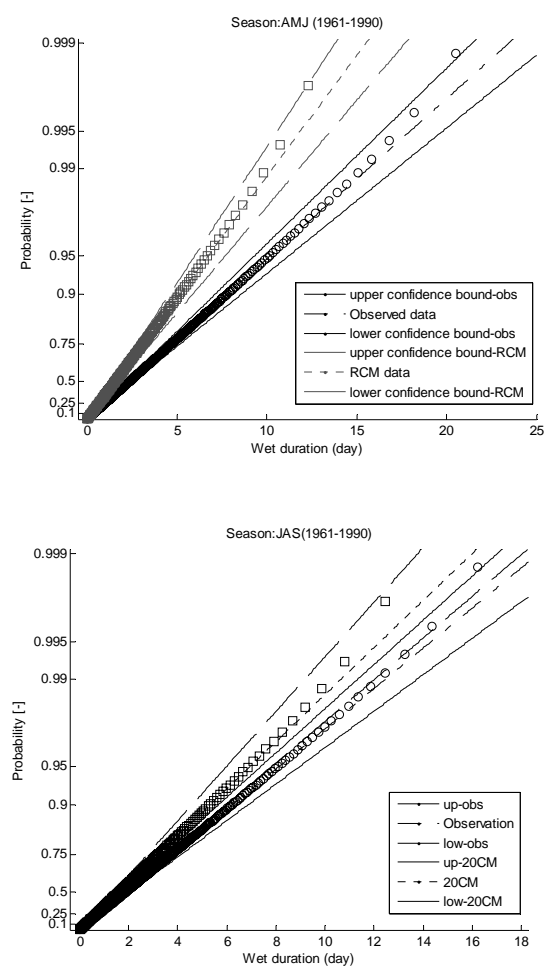

d)

spring and summer inter-storm periods, and an overall underestimation of the mean storm intensity.

In comparing the PRP parameters derived from the RCM dataset and the observations, the non-parametric Wilconox rank sum method was employed in order to test the statistical meaningfulness of the equality of the two means. This test was performed at a $95 \%$ confidence level to the RCM and observed daily rainfall time-series regarding the reference period (1961-1990). The bias in the means was expressed as $p$-value (probability, under the null hypothesis, to obtain a value of the test statistic as high or higher than the value computed from the sample) in Table 2. Statistically meaningful biases were found for dry periods in the autumn, spring and summer seasons, wet periods in spring season, and for storm intensity in autumn and spring seasons (p-values below 0.05).

The ability of the PRP model to generate realistic series of daily rainfall at the grid-cell scale was validated by testing the distributional agreement between the observations and the simulated records referred to the calibration period (1961-1990). To this goal, the two-sample KolmogorovSmirnov goodness-of-fit test was performed to the samples of dry and wet periods, and storm intensity. The probability of the Kolmogorov-Smirnov Z statistic fell well above the 0.05 threshold for the statistics concerning inter-storm and storm durations (Table 4) providing the evidence of a good capability of the PRP scheme to correct the intermittency structure 
a)
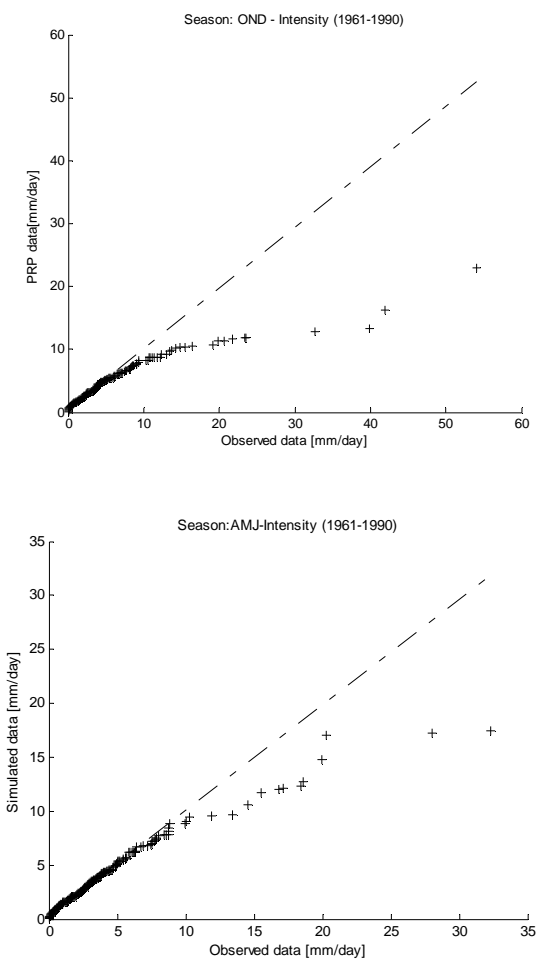

b)

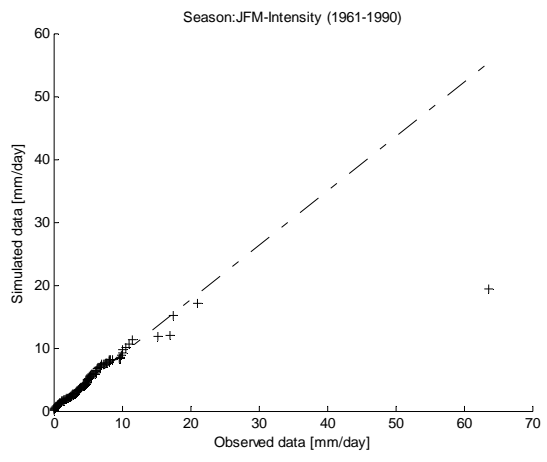

d)

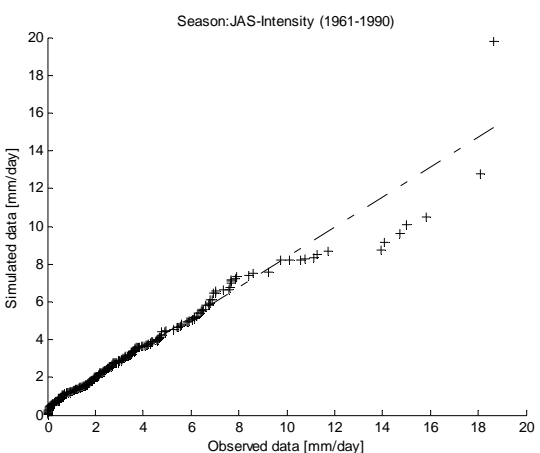

Fig. 6. The distributional agreement of storm intensity is represented by the qq-plots between observations and RCM bias-corrected data corresponding to the calibration period (1961-1990) in the autumn season (a), in the winter season (b), in the spring season (c), and in the summer season (d).

a)

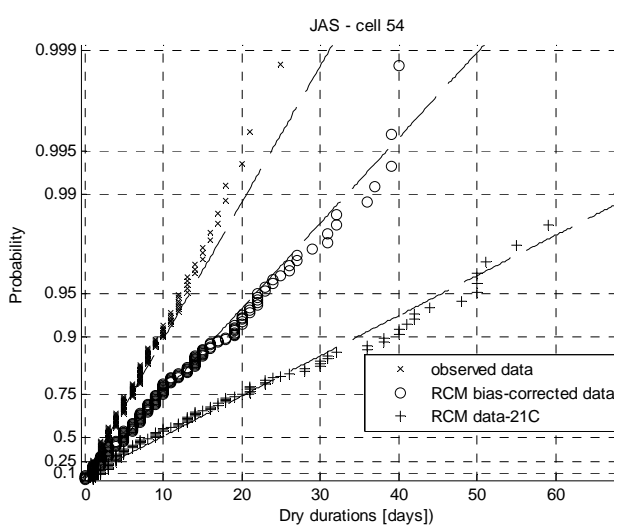

b)

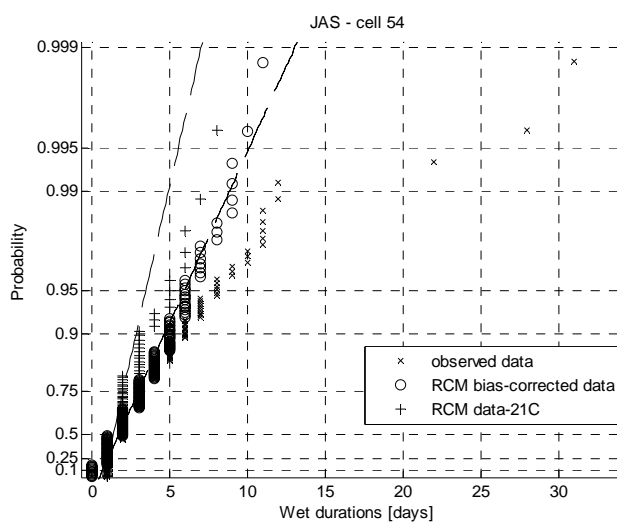

Fig. 7. Exponential probability plots of the dry (a) and wet (b) periods obtained for a grid-cell using the PRP stochastic model in the summer season (marked with circles); with dashed lines the theoretical distributions estimated for the reference observations, the row RCM data, and RCM bias-corrected data for the 21 st Century are reported respectively.

of daily rainfall. On the contrary, the reproduction of daily storm intensity after correction was still unsatisfactory particularly in the autumn season as represented in the quantile comparison plots in Fig. 6.
Finally, the expected alteration of the rainfall regime (under the Alb scenario) was derived using Eq. (1) from the scale factors of the aforesaid storm statistics between the 21 st century run and the control run. Among the major findings in the downscaled rainfall scenario for the $21 \mathrm{st}$ 


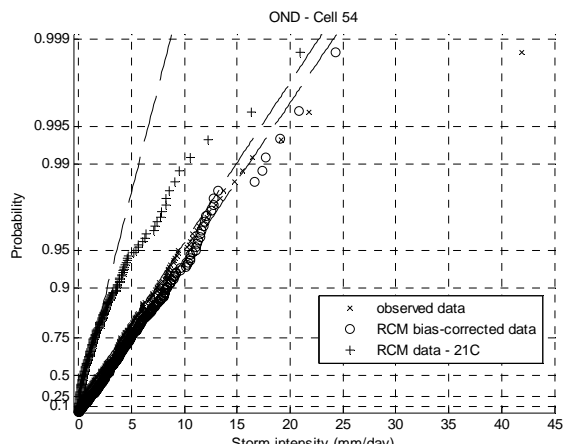

a)

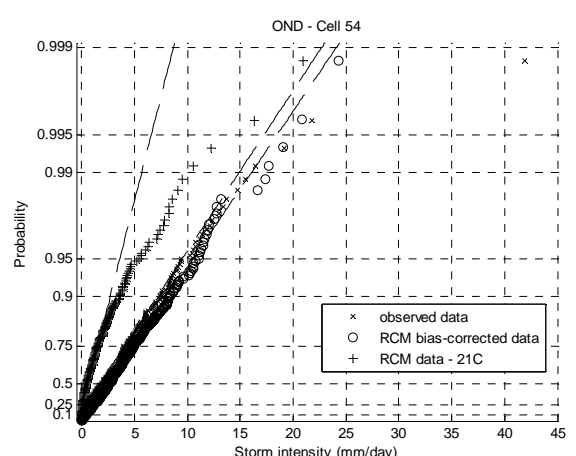

b)

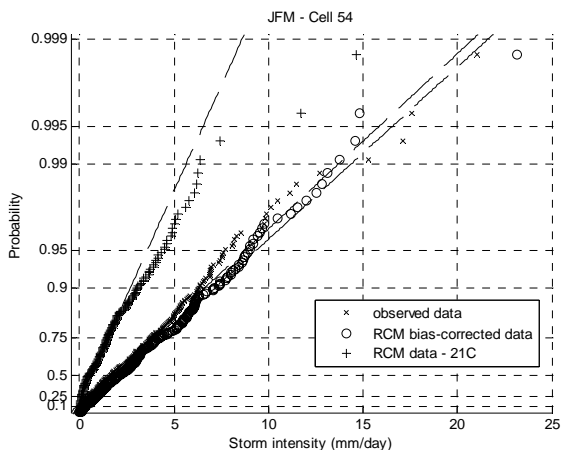

b)

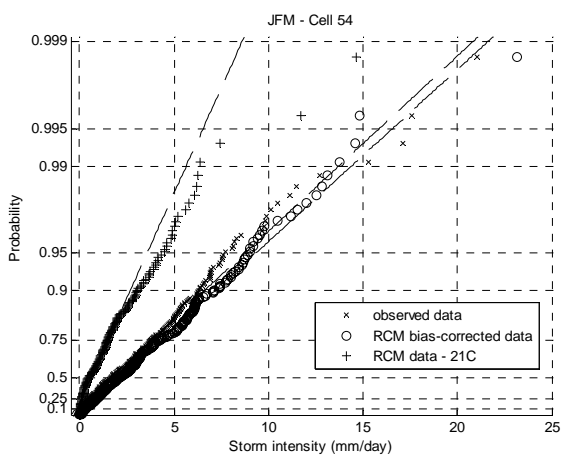

a)

Fig. 8. Exponential probability plots of the daily storm intensities obtained for a grid-cell using the PRP stochastic model for autumn (a), winter (b), spring (c) and summer (d). The dashed lines represent the theoretical distributions estimated for the reference observations, the row RCM data, and RCM bias-corrected data for the 21st Century respectively.

Table 1. Analysis of RCM predictive performance through the assessment of the model/observation bias of the following storm parameters: mean storm intensity $\left(\mu_{I}\right)$, mean wet period $\left(\delta_{w}\right)$ and mean dry period $\left(\delta_{d}\right)$. The parameters are computed seasonally for the reference period 1961-1990.

\begin{tabular}{llllll}
\hline SEASON & & OND & JFM & AMJ & JAS \\
\hline$\delta_{d}$ [days] & OBS & 2.55 & 2.45 & 3.10 & 4.25 \\
& RCM & 2.83 & 2.92 & 7.69 & 8.69 \\
& Bias=RCM/OBS & 1.11 & 1.19 & 2.48 & 2.04 \\
$\delta_{w}$ [days] & OBS & 4.36 & 4.61 & 3.38 & 2.73 \\
& RCM & 4.20 & 4.24 & 2.27 & 2.35 \\
& Bias=RCM/OBS & 0.96 & 0.92 & 0.67 & 0.86 \\
$\mu_{I}$ & OBS & 3.02 & 2.58 & 2.48 & 2.43 \\
{$[\mathrm{~mm} /$ day $]$} & RCM & 1.06 & 1.12 & 1.17 & 1.84 \\
& Bias=RCM/OBS & 0.35 & 0.44 & 0.69 & 0.76 \\
\hline
\end{tabular}

Century (Table 4), the mean inter-storm period is predicted to increase by $70 \%$ in summer and $13 \%$ in autumn; the mean storm duration is predicted to decrease by $15 \%, 11 \%$ and $12 \%$ respectively in autumn, winter and summer; and the mean storm intensity is expected to slightly decrease in spring, while an increase in summer $(14 \%)$, autumn $(21 \%)$ and winter $(10 \%)$ is predicted.
Table 2. $P$-value results of the Wilconox rank sum test for the difference of means between observed and RCM data (reference period 1961-1990) at a 95\% confidence level.

\begin{tabular}{lllll}
\hline$p$-value & OND & JFM & AMJ & JAS \\
\hline Dry periods & 0.04 & 0.05 & 0 & $2.06 \times 10^{-6}$ \\
Wet periods & 0.71 & 0.36 & $6.26 \times 10^{-5}$ & 0.20 \\
Storm intensity & $1.6 \times 10^{-19}$ & 0 & $5.00 \times 10^{-4}$ & 0.02 \\
\hline
\end{tabular}

Table 3. Expected change factors of the storm statistics due to the alteration of the rainfall regime (A1b scenario) between the $21 \mathrm{st}$ century RCM run (2003-2030) and the reference RCM run (19611990).

\begin{tabular}{llll}
\hline SEASON & $\Delta d$ & $\Delta w$ & $\Delta I$ \\
\hline OND & 1.13 & 0.85 & 1.21 \\
JFM & 1.01 & 0.89 & 1.10 \\
AMJ & 1.02 & 1.08 & 0.88 \\
JAS & 1.69 & 0.82 & 1.14 \\
\hline
\end{tabular}




\section{Table 4.}

P-value results of the Kolmogorov-Smirnov goodness-of-fit test for the assessment of distributional agreement between the reference observations and the PRP-modelled rainfall after the bias correction.

\begin{tabular}{lllll}
\hline$p$-value & OND & JFM & AMJ & JAS \\
\hline Dry periods & 0.196 & 0.771 & 0.983 & 0.167 \\
Wet periods & 0.407 & 0.990 & 0.190 & 0.620 \\
Storm intensity & 0.000 & 0.003 & 0.004 & 0.000 \\
\hline
\end{tabular}

As a conclusion of the proposed downscaling approach, the re-scaled PRP parameters were used as input to a Montecarlo rainfall generator producing statistically homogeneous time series (Figs. 7 and 8). Compared to the 20th Century's observations, the obtained rainfall scenario (20032030, A1B) for the study area is characterized by longer dry seasons, less rain in autumn and winter and heavier rain events in summer and autumn. Nevertheless the produced rainfall scenario after the bias correction was closer to the observations (reference period) than the RCM output. The large distance between the raw and post-processed scenarios obtained at the local scale (corresponding to one grid-cell) underlined the need to apply suitable bias correction methods to obtain more realistic input data to be used in climate change impact studies.

\section{Conclusions}

The analysis of the rainfall intermittency features at daily scale provide a clear picture of the capability of climate models to predict daily precipitation in terms of wet and dry alternations and storm intensity against rainfall observations. At the same time this type of analysis can be summarized into few statistical parameters representing the process complexity. By assuming the PRP scheme, only three parameters are needed to represent the point rainfall process encompassing both ordinary and extreme weather conditions (i.e. heavy storms and droughts).

The comparison between modeled and observed rainfall in terms of storm parameters allows for a bias-free assessment of climate change through the relative measure of alteration in the wet/dry periods and storm intensity. This approach has also immediate application in the development of stochastic weather generators which are recognized as an effective operational tool to downscale RCM predictions at the local scale. The structure of the PRP model for the synthetic generator of rainfall records allows to reproduce internally consistent climate records of any required length in order to evaluate the hydrological impacts that may occur under ordinary and extreme weather conditions.
Acknowledgements. This work was conducted within the CIRCE Integrated Project supported by the European Commission's Sixth Framework Programme (Project No. 036961).

Edited by: M.-C. Llasat

Reviewed by: one anonymous referee

\section{References}

Burlando, R. and Rosso, R.: Extreme storm rainfall and climate change, Atmos. Res., 27, 71-84, 1991.

Burlando R, and Rosso, R.: Effects of transient climate change on basin hydrology. 1. Precipitation scenarios for the Arno River, central Italy, Hydrol. Proc. 16, 1151-1175, 2002.

Deidda, R.: Rainfall downscaling in a spacetime multifractal framework, Water Resour. Res., 36(7), 1779-1784, 2000.

Deidda, R., Badas, M. G., and Piga, E.: Spacetime Multifractality of Remotely Sensed Rainfall Fields, J. Hydrol., 322, 2-13, 2006.

Déqué, M.: Frequency of precipitation and temperature extremes over France in a anthropogenic scenario: model results and statistical correction according to observed values, Global Planet. Change, 54(1-2), 16-26, 2007.

Eagleson, P. S.: Climate, Soil, and Vegetation 2. The Distribution of Annual Precipitation Derived From Observed Storm Sequences, Water Resour. Res., 14(5), 713-721, 1978.

Gualdi, S., Rajkovic, B., Djurdjevic, V., Castellari, S., Scoccimarro, E., Navarra, A. and Dacic, M.: SINTA, SImulations of climate chaNge in the mediTerranean Area, Final scientific report, INGV, 2008.

Kilsby, C. G., Jones, P. D., Burton, A., Ford, A. C., Fowler, H. J., Harpham, C., James, P., Smith and A., Wilby, R. L. A daily weather generator for use in climate change studies, Environ. Model. Softw., 22, 1705-1719, 2007.

Kottegoda, N. T. and Rosso, R.: Applied Statistics for Civil and Environmental Engineers, second ed., Wiley-Blackwell, Oxford, 517-519, 2008.

Rodriguez-Iturbe, I., Cox, D. R., and Isham, V.: Some models for rainfall based on stochastic point processes, Proc. R. Soc. Lond. Ser. A, 410, 269-288, 1987.

Salsón, S. and Garcia-Bartual, R.: A space-time rainfall generator for highly convective Mediterranean rainstorms, Nat. Hazards Earth Syst. Sci., 3, 103-114, doi:10.5194/nhess-3-103-2003, 2003. 